ARTICLE

Received 4 Jul 2014 | Accepted 15 Oct 2014 | Published 2 Dec 2014

DOI: $10.1038 /$ ncomms 6574

OPEN

\title{
Three-dimensional periodic supramolecular organic framework ion sponge in water and microcrystals
}

Jia Tian' ${ }^{1}$, Tian-You Zhou ${ }^{2}$, Shao-Chen Zhang ${ }^{1}$, Shaul Aloni ${ }^{3}$, Maria Virginia Altoe ${ }^{3}$, Song-Hai Xie ${ }^{1}$, Hui Wang ${ }^{1}$, Dan-Wei Zhang ${ }^{1}$, Xin Zhao ${ }^{2}$, Yi Liu ${ }^{3} \&$ Zhan-Ting Li ${ }^{1}$

Self-assembly has emerged as a powerful approach to generating complex supramolecular architectures. Despite there being many crystalline frameworks reported in the solid state, the construction of highly soluble periodic supramolecular networks in a three-dimensional space is still a challenge. Here we demonstrate that the encapsulation motif, which involves the dimerization of two aromatic units within cucurbit[8]uril, can be used to direct the co-assembly of a tetratopic molecular block and cucurbit[8]uril into a periodic three-dimensional supramolecular organic framework in water. The periodicity of the supramolecular organic framework is supported by solution-phase small-angle X-rayscattering and diffraction experiments. Upon evaporating the solvent, the periodicity of the framework is maintained in porous microcrystals. As a supramolecular 'ion sponge', the framework can absorb different kinds of anionic guests, including drugs, in both water and microcrystals, and drugs absorbed in microcrystals can be released to water with selectivity.

\footnotetext{
${ }^{1}$ Collaborative Innovation Center of Chemistry for Energy Materials (iChEM), Department of Chemistry, Fudan University, 220 Handan Road, Shanghai 200433, China. ${ }^{2}$ Laboratory of Synthetic and Self-Assembly Chemistry for Organic Functional Molecules, Shanghai Institute of Organic Chemistry, Chinese Academy of Sciences, 345 Lingling Lu, Shanghai 200032, China. ${ }^{3}$ The Molecular Foundry, Lawrence Berkeley National Laboratory, One Cyclotron Road, Berkeley, California 94720, USA. Correspondence and requests for materials should be addressed to D.-W.Z. (email: zhangdw@fudan.edu.cn) or to Y.L. (email: yliu@|bl.gov) or to Z.-T.L. (email: ztli@fudan.edu.cn).
} 
$\mathrm{n}$ the last four decades, an enormous body of research has been amassed on the topics of supramolecular chemistry and self-assembly ${ }^{1,2}$. Recently, considerable effort has been devoted to crystal engineering ${ }^{3}$ and supramolecular polymers ${ }^{4,5}$ for better control of bonding and ordering. By utilizing coordination or hydrogen bonding as driving forces, a large number of supramolecular crystalline frameworks ${ }^{6}$, including a hydrogen bonding-stabilized supramolecular organic framework $(\mathrm{SOF})^{\gamma}$, have been constructed, many of which generate channels that allow for gas, solvent or guest absorption ${ }^{7-9}$. However, none of these crystalline frameworks can maintain their periodicity in solution. Supramolecular polymers $4,5,10-18$, particularly these based on tetrahedral building blocks ${ }^{19-22}$, can produce threedimensional (3D) cross-linked networks in solution. However, these networks generally lack periodicity in a $3 \mathrm{D}$ space. To the best of our knowledge, there are no prior examples of solutionphase $3 \mathrm{D}$ periodic supramolecular networks, although a solutionphase two-dimensional (2D) periodic supramolecular framework had been created by $\mathrm{us}^{23}$. The past two decades have also witnessed great advance in the design of $3 \mathrm{D}$ metal-organic frameworks ${ }^{24,25}$ and covalent organic frameworks based on strong coordination or covalent bonds ${ }^{26,27}$. Currently, such hard porous solid-state architectures have been vigorously studied for various functions or applications ${ }^{28,29}$, in particular, in gas storage $^{30,31}$, absorption and separation ${ }^{32,33}$, recognition and sensing ${ }^{34,35}$, biomedical science ${ }^{36-38}$ and catalysis ${ }^{39-41}$. If selfassembly can be shown to drive the formation of periodic supramolecular networks in a $3 \mathrm{D}$ space in solution, rational design of molecular building blocks should lead to the construction of a variety of soluble ordered porous frameworks and thus offer new opportunities for the generation of advanced soft materials.

Herein, we report the first example of solution-phase selfassembly of a $3 \mathrm{D}$ periodic porous $\mathrm{SOF}$ in water, utilizing the encapsulation of cucurbit[8]uril $(\mathrm{CB}[8])$ for two 4-(4methoxyphenyl)pyridin-1-ium (PP) units. The periodic SOF not only exists in solution, but also can be maintained in the solid state. We further demonstrate that the porous framework, as a family of 3D-ordered cationic supramolecular polyelectrolyte, can attract a variety of anionic organic molecules, including dyes, drugs, peptides, nucleic acids and poly(amidoamine) (PAMAM) dendrimers, in both solution and the solid state, and the attracted drugs can be released to water selectively in acidic medium.

\section{Results}

The design of target and control molecules. Pioneering work by Kim et al. ${ }^{42}$ established that CB[8] stabilizes the charge-transfer interaction between two different aromatic units in aqueous media. Recently, Zhao reported that $\mathrm{CB}[8]$ also enhances the homodimerization of 4-arylpyridin-1-ium units through hydrophobicity ${ }^{43}$. We thus designed and prepared compound 1 for assembling 3D SOF by utilizing the 1:2 binding motif between $\mathrm{CB}[8]$ and 4-(4-methoxyphenyl)pyridin-1-ium (PP) unit (Fig. 1). Three PP-containing compounds 2-4 were prepared as controls (Fig. 1).

Spectroscopic and and mass spectrometric studies. The binding of the PP units of 1-4 by $\mathrm{CB}[8]$ in $\mathrm{D}_{2} \mathrm{O}$ was first studied by ${ }^{1} \mathrm{H}$ nuclear magnetic resonance (NMR) spectroscopy (Supplementary Figs $1-4)$. For the $2: 1$ solution of $2(8.0 \mathrm{mM})$ and $\mathrm{CB}[8]$, at $25^{\circ} \mathrm{C}$, the signals of the $\beta$-protons of the pyridinium unit and the protons of the connected benzene unit disappeared, while other signals became broader compared with those of $\mathbf{2}$ in the absence of $\mathrm{CB}[8]$. Reducing the temperature to $5^{\circ} \mathrm{C}$ led to the splitting of several aromatic proton signals, although the signals were
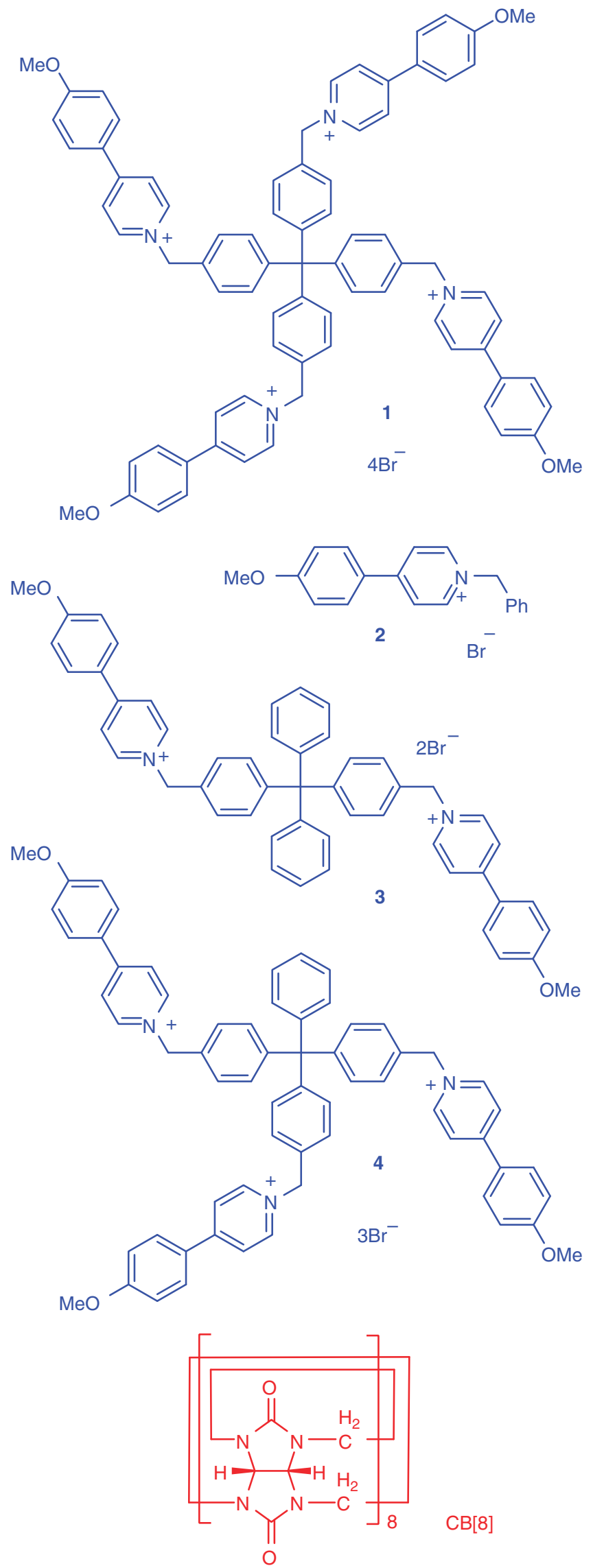

Figure 1 | Compounds used in this study. The structures of compounds 1-4 and $C B[8]$. 
all broad. These observations suggest that two complexation patterns, that is, the head-to-tail and head-to-head stacking of 2 within the cavity of $\mathrm{CB}[8]$, existed, although the crystal structures of the 2:1 complexes of two model molecules with $\mathrm{CB}[8]$ exhibited the head-to-tail stacking pattern ${ }^{43}$. The ${ }^{1} \mathrm{H}$ NMR spectrum of the $1: 1$ solution of $3(4.0 \mathrm{mM})$ and $\mathrm{CB}[8]$ indicated the formation of one major species and a minor one, which were assigned to the two isomers of a $2+2$ macrocyclic complex $3_{2} \bullet \mathrm{CB}_{2}$ (Com-D, Fig. 2a) that coalesced at high temperature (Supplementary Fig. 3). Dynamic light-scattering (DLS) experiments for the 1:1 solution of 3 and $\mathrm{CB}[8]$ revealed that the hydrodynamic diameter $\left(D_{\mathrm{H}}\right)$ of the complex formed by them did not change at elevated temperature (Supplementary Fig. 21e-g). This observation is consistent with the above ${ }^{1} \mathrm{H}$ NMR experiments at high temperature, because the proposed isomers of COM-D were expected to possess comparable size. The formation of such $2+2$ complex was further confirmed by the ionic peak of $\left[3_{2} \bullet \mathrm{CB}_{2}\right.$ $3 \mathrm{Br}]^{3+}$ at $m / z=1,389.4648$ (calculated value: 1,389.4608) from the electrospray ionization mass spectrometry (Supplementary Fig. 5). The ${ }^{1} \mathrm{H}$ NMR spectrum of the $2: 3$ solution of $\boldsymbol{4}(2.7 \mathrm{mM})$ and $\mathrm{CB}[8]$ gave one set of signals associated with encapsulated 4, and the addition of more $\mathrm{CB}[8]$ did not cause the signals to shift or the appearance of new signals. These signals were tentatively assigned to 4 in a stable and symmetric $4+6$ capsular complex $4_{4} \bullet \mathrm{CB}_{6}$ (Com-Tri, Fig. 2b), because the modelled size of this complex matched the $D_{\mathrm{H}}$ of the species measured by DLS (vide infra). In contrast, the ${ }^{1} \mathrm{H}$ NMR spectrum of the $1: 2$ solution of $1(2.0 \mathrm{mM})$ and $\mathrm{CB}[8]$ displayed very broad signals, which remained unchanged at higher temperature or with more equivalent of $\mathrm{CB}[8]$. These observations implied the formation
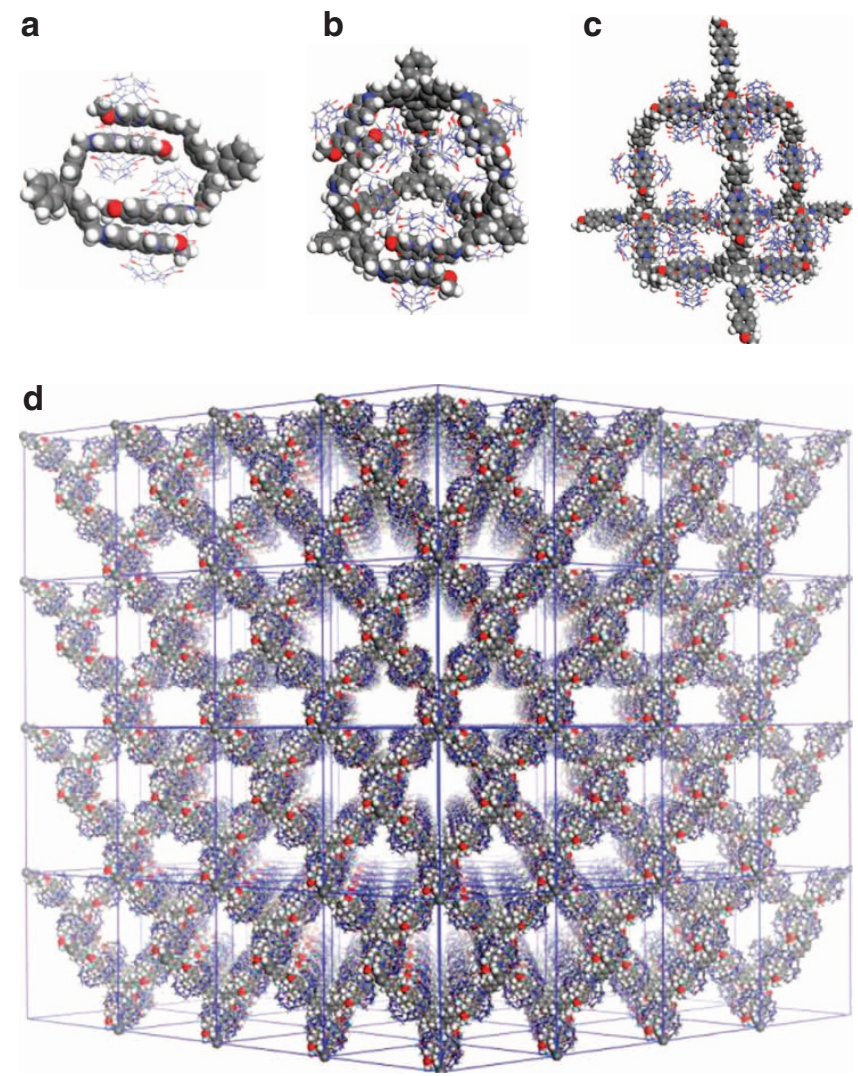

Figure 2 | Self-assembled patterns. (a) Model of the $2+2$ macrocycle $\mathbf{3}_{2} \bullet \mathrm{CB}_{2}$ (Com-D). (b) Model of the $4+6$ capsule $\mathbf{4}_{4} \bullet \mathrm{CB}_{6}$ (Com-Tri). $(\mathbf{c}, \mathbf{d})$ Models of one adamantane-shaped unit and the 3D supramolecular organic framework $\left(\mathbf{1}_{n} \bullet \mathrm{CB}_{2 n}\right.$, Com-Tetra). of a more complicated supramolecular structure $\mathbf{1}_{\mathrm{n}} \bullet \mathrm{CB}[8]_{2 \mathrm{n}}$ (Com-Tetra, Fig. 2c). The 2:1 binding stoichiometry of the PP units of 1-4 and $\mathrm{CB}[8]$ was further confirmed by Job's plots using fluorescence spectroscopy (Supplementary Figs 6-9). Using the competition ${ }^{1} \mathrm{H}$ NMR method reported by Isaacs ${ }^{44}$, we determined the apparent association constant $\left(K_{\mathrm{a}}\right)$ of the $2: 1$ complex between the PP unit of $2,3,4$ and $\mathbf{1}$ and $\mathrm{CB}[8]$ to be $1.1 \times 10^{11}, 9.4 \times 10^{11}, 5.4 \times 10^{12}$ and $1.3 \times 10^{14} \mathrm{M}^{-2}$, respectively, in $50 \mathrm{mM} \mathrm{CD} \mathrm{CO}_{2} \mathrm{Na}$-buffered $\mathrm{D}_{2} \mathrm{O}(\mathrm{pD}=4.74)$. The fact that the values increased substantially in the order of $\mathbf{2}<\mathbf{3}<\mathbf{4}<\mathbf{1}$ excluded the formation of disordered supramolecular polymers by 3,4 and $\mathbf{1}$ because the encapsulation in their systems exhibited considerable positive cooperativity. For $\mathbf{4}$ and $\mathbf{1}$, the results may also be rationalized by considering the formation of an ordered $2 \mathrm{D}$ or $3 \mathrm{D}$ supramolecular network ${ }^{23}$, which is expected to enhance the stability of the 2:1 complex. However, DLS experiments, which gave a small $D_{\mathrm{H}}$ of $4.0 \mathrm{~nm}$ for the mixture of 4 (vide infra), excluded the possibility of forming a $2 \mathrm{D}$ network by 4 .

2D ${ }^{1} \mathrm{H}$ NMR diffusion-ordered spectroscopic (DOSY) experiments were performed for the solution of the four mixtures $([\mathrm{PP}] /[\mathrm{CB}[8]]=2,[\mathrm{PP}]=4.0 \mathrm{mM})$ in $\mathrm{D}_{2} \mathrm{O}$ (ref. 45). In all four spectra, the signals of the complexes gave rise to the nearly identical diffusion coefficient $(D)$, which was $2.5 \times 10^{-10}, 1.7 \times 10^{-10}, 1.4 \times 10^{-10}$ and $4.8 \times 10^{-11} \mathrm{~m}^{2} \mathrm{~s}^{-1}$ (Supplementary Figs 10-14), respectively. The notably lower $D$ values of complexes Com-D and Com-Tri, compared with that of Com-M, indicated the formation of larger aggregates. The value of Com-Tetra was considerably lower than that of Com-Tri, suggesting that it produced even larger supramolecular aggregates. From DLS experiments in water conducted for the four mixtures at $[\mathrm{PP}]=6.0 \mathrm{mM}$, we determined the $D_{\mathrm{H}}$ values of the four mixtures to be $1.4,2.9,4.0$ and $91.3 \mathrm{~nm}$, respectively (Supplementary Figs 21a-d), the order of which was in agreement with the above DOSY results. The $D_{\mathrm{H}}$ values of Com-D and Com-Tri were pronouncedly larger than that of Com-M and reasonably matched with the calculated sizes of their respective $2+2$ macrocycle (ca. $3.0 \mathrm{~nm}$ ) and $4+6$ capsule (ca. $4.1 \mathrm{~nm})$. The result also excluded the formation of large extended networks by Com-Tri ${ }^{23}$. Remarkably, the $D_{\mathrm{H}}$ of Com-Tetra was $>20$ times larger than that of Com-Tri, which clearly indicated the formation of a large complex in the mixture of 1 and $\mathrm{CB}$ [8]. The $D_{\mathrm{H}}$ value for the solution of Com-Tetra also increased with the concentration and reached $100.5 \mathrm{~nm}$ at $[\mathrm{PP}]=8.0 \mathrm{mM}$ (Supplementary Fig. 22). Further increase of the concentration resulted in the formation of a hydrogel (Supplementary Fig. 38). Similar concentration dependence was not observed for Com-M, Com-D and Com-Tri, which was consistent with that they just produced small aggregates.

The characterization of 3D supramolecular structures. An ideal 3D supramolecular network formed by Com-Tetra would resemble the $3 \mathrm{D}$ net of diamond. The central carbon atom of $\mathbf{1}$ is the vertex of the net, and $\mathrm{CB}[8]$ locks two PP units of neighbouring molecules by holding them in its cavity. We then simulated the crystal structure of the 3D supramolecular network from the diamond topology using Materials Studio 5.0 (ref. 46), on the basis of the crystal structure parameters of the $2: 1$ complex of 4-(4-methoxyphenyl)pyridin-1-ium and $\mathrm{CB}[8]^{43,47}$. The obtained structure is shown in Fig. 2d. Considering the tetrahedral feature of compound $\mathbf{1}$ and the growth of the framework occurred in the $3 \mathrm{D}$ space, we conjecture that the aggregates formed in solution should be roughly spherical.

To investigate the solution-phase periodicity of the $3 \mathrm{D}$ supramolecular network formed by Com-Tetra, we first carried 
out a small-angle X-ray-scattering (SAXS) experiment for the solution in water, which revealed a broad but clear peak corresponding to the d-spacing around $5.1 \mathrm{~nm}$ (Supplementary Fig. 23). This spacing matched well with the calculated $\{100\}$ spacing $(4.9 \mathrm{~nm})$ of the modelled network, providing the first evidence for the periodicity of the 3D SOF in solution. When the solution was subjected to synchrotron radiation X-ray scattering, a much stronger peak corresponding to the d-spacing of $5.0 \mathrm{~nm}$ was observed, together with another broad peak with d-spacing of ca. $2.6 \mathrm{~nm}$ (Fig. 3a). This peak could be assigned to the $\{200\}$ spacing, which has a calculated value of $2.5 \mathrm{~nm}$. These results further confirmed the periodicity of the 3D SOF in solution. Synchrotron X-ray diffraction studies of the same solution also revealed a broad peak around $1.7 \mathrm{~nm}$ and a relatively sharp peak around $1.0 \mathrm{~nm}$ (Fig. 3b), which are again in agreement with the expected spacing $(1.7 \mathrm{~nm})$ of the $\{220\}$ face and the spacing $(1.0 \mathrm{~nm})$ of the $\{422\}$ face of the $3 \mathrm{D}$ SOF. The differences between the calculated and measured $\mathrm{d}$-spacing may indicate solvent-induced expansion, and reflect the dynamic feature of the supramolecular frameworks in solution. The broad peaks in Fig. 3a,b may also reflect this dynamic feature.
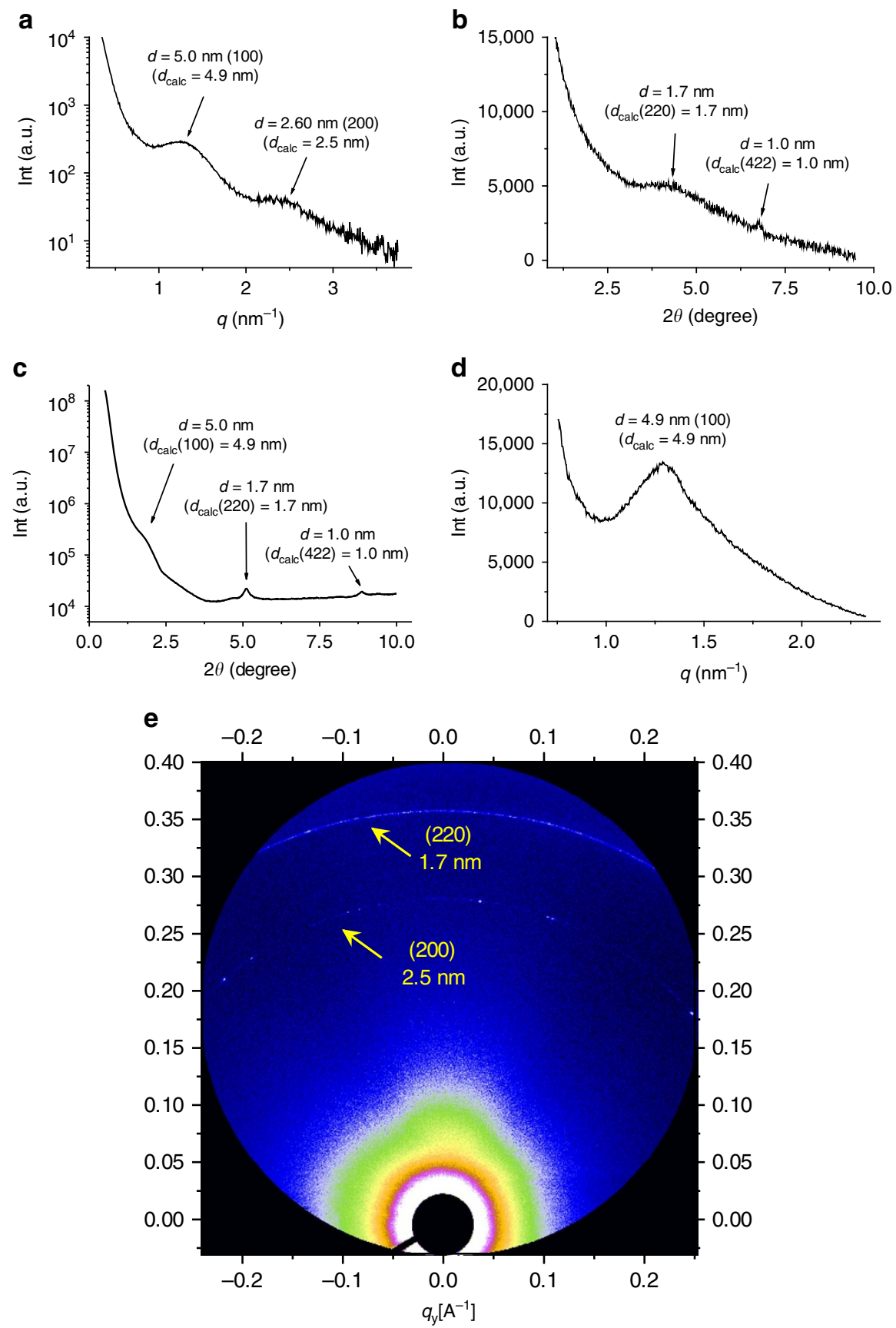

Figure 3 | Solution- and solid-phase SAXS and X-ray diffraction profiles. (a) Solution-phase synchrotron small-angle X-ray-scattering profile of the solution of Com-Tetra ([PP] $=8 \mathrm{mM}$ ) in water. (b) Solution-phase synchrotron X-ray diffraction (XRD) profile in water. (c) XRD profile of the solid sample obtained by evaporating the solution of Com-Tetra in water. The peak value was attributed by choosing the position that is highest above the straight line defined by the two saddle points of the broad peak. (d) Small-angle synchrotron X-ray-scattering profile of Com-Tetra of the solid sample. (e) Two-dimensional synchrotron X-ray-scattering profile of Com-Tetra of the solid sample. 
During slow evaporation under ambient temperature, the above solution first turned into a hydrogel, and then slowly solidified due to further loss of the solvent. Scanning electron microscope images revealed that the solidification was accompanied with microcrystallization of the sample, which was evidenced by selected area electron diffraction (SAED) experiments (Fig. $4 \mathrm{a}-\mathrm{c}$, inset). The X-ray diffraction profile of the microcrystals exhibited three peaks centred at 5.0, 1.7 and $1.0 \mathrm{~nm}$ (Fig. 3c), respectively, which matched well with the $\{100\},\{220\}$ and $\{422\}$ spacings of the modelled $3 \mathrm{D}$ framework (Fig. 2d). This result supported that the periodicity of the $3 \mathrm{D}$ SOF not only existed in solution, but also could be maintained in the solid state. Since the 100 peak in Fig. 3c was very weak, we further performed small-angle synchrotron X-ray scattering of Com-Tetra of the solid sample (Fig. 3d). A much stronger peak centred at $4.9 \mathrm{~nm}$, corresponding to the $\{100\}$ spacing, was exhibited. Twodimensional synchrotron X-ray scattering was also carried out for the solid sample, which revealed two scattering peaks with d-spacings of 2.5 and $1.7 \mathrm{~nm}$ (Fig. 3e), which again matched well with the calculated values of the $\{200\}$ and $\{220\}$ spacings. High-resolution transmission electron microscopy (TEM) of the microcrystal revealed periodic porosity with $1.7-\mathrm{nm}$ spacing (Fig. 4d), which also matched well with the simulated value $(1.7 \mathrm{~nm})$ for the $\{220\}$ face. Thermogravimetric analysis showed that the supramolecular microcrystals were stable at a high temperature of $300^{\circ} \mathrm{C}$ (Supplementary Fig. 40).

On the basis of the X-ray diffraction and TEM results and the parameters of the single crystal of the $1: 2$ complex of $\mathrm{CB}[8]$ and 1-methyl-4-(4-methoxyphenyl)pyridin-1-ium, we could determine the cubic unit-cell metrics $(a=b=c=49.2 \AA$, $\alpha=\beta=\gamma=90^{\circ}$ ). SAED patterns of the microcrystals with the reciprocal lattice observed for the $\{100\}$ and $\{111\}$ facets showed high foursquare and hexagonal order, respectively (Fig. 4e,f), which further confirmed the cubic unit cell of the microcrystals. The SAED pattern, that is, $1.7 \mathrm{~nm}$ for $\{220\}$ lattice spacing, matched well with the simulated datum $(1.7 \mathrm{~nm})$. Elemental mapping analysis for the microcrystals also confirmed the compositions of the $\mathrm{C}, \mathrm{N}, \mathrm{O}$ and $\mathrm{Br}$ elements (Supplementary Fig. 24).

Absorption studies. The calculated void volume of the 3D SOF based on the above model was about $77 \%$, which suggested high porosity. The pore aperture, defined by the six $\mathrm{CB}[8]$ units in one self-assembled macrocycle adopting a cyclohexane-like chair conformation, was calculated to be about $2.1 \mathrm{~nm}$, while the size defined by the adamantane-like self-assembled cage was ever larger. Given the polycationic feature of this 3D framework, we envisioned that it should be able to attract organic anionic guests in solution by electrostatic interactions. We thus evaluated its inclusion property towards 20 different anionic guests of varying shape and size (Fig. 5), including dyes, drugs, peptides, sDNA and DNA and dendrimers. A systematic investigation of guestinduced fluorescent quenching of the PP unit was then performed, which allowed us to evaluate the inclusion capacity of 3D SOF against the other three discrete $\mathrm{PP} / \mathrm{CB}[8]$ supramolecular
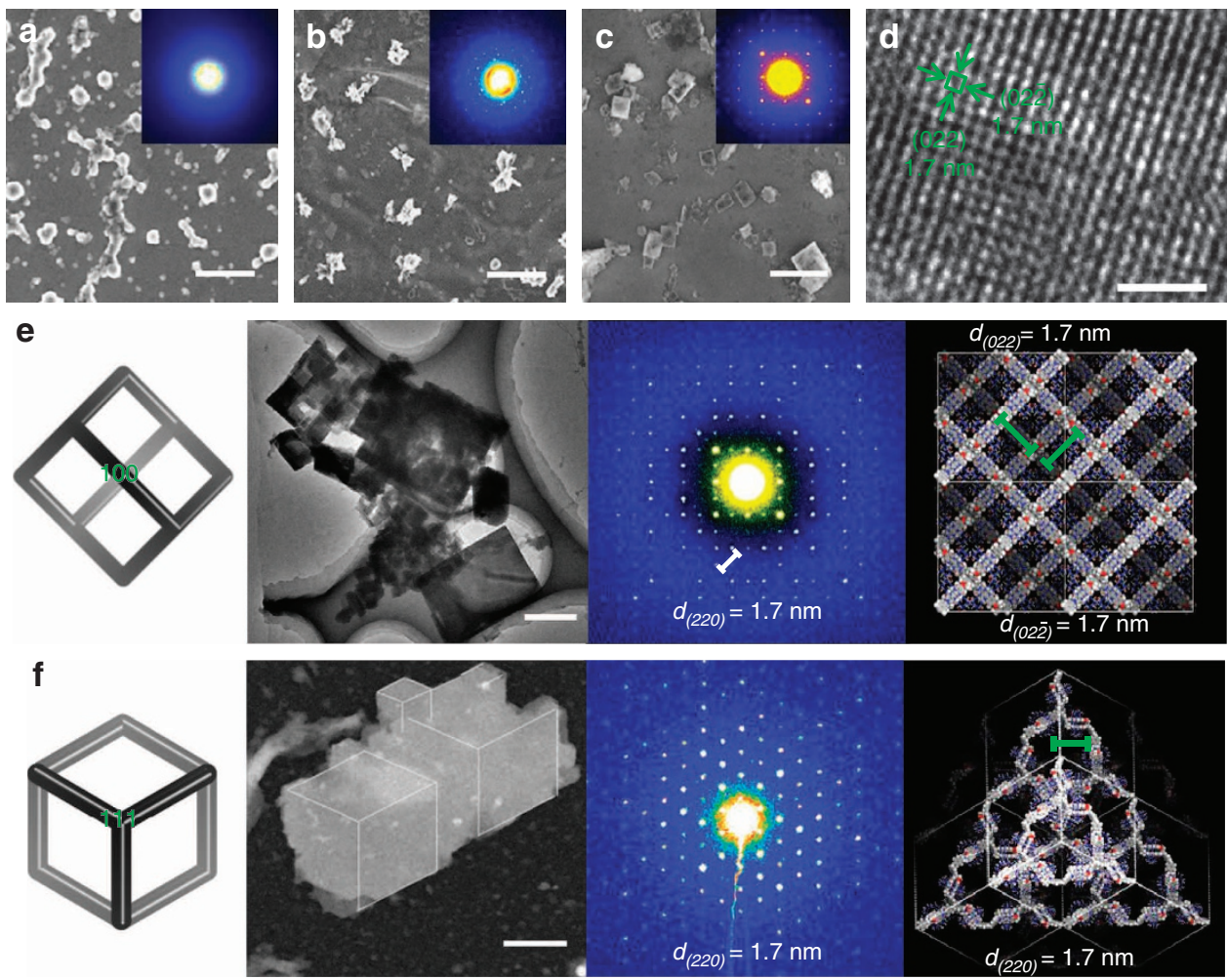

Figure 4 | Electron microscopy and SAED. Scanning electron microscope (SEM) images, high-resolution TEM image and SAED pattern with model illustration. (a-c) SEM images of Com-Tetra recorded right after evaporation of the solvent, and after standing for 3 and 14 days (bar width $=1 \mu \mathrm{m}$ ). The images highlighted microcrystallization of the sample. Inset: SAED patterns showing the different ordering at different time. (d) High-resolution TEM image of the periodic porous pattern of the microcrystal (bar width $=10 \mathrm{~nm}$ ). (e) Schematic illustration and Cryo-TEM (left two images of panel, bar width $=0.5 \mu \mathrm{m}$ ), and SAED pattern and its model illustration (right two images of panel) of the microcrystals with the reciprocal lattice observed for the $\{100\}$ facet, which showed foursquare order. (f) Schematic illustration and Cryo-TEM (left two images of panel, the white lines in the TEM image are eyeguides (bar width $=0.3 \mu \mathrm{m}$, Supplementary Fig. 39), and SAED pattern and its model illustration (right two images of panel) of the microcrystal with the reciprocal lattice for the $\{111\}$ facet, which showed hexagonal order. 
<smiles>O=S(=O)(O[Na])c1ccc2cc(S(=O)(=O)O[Na])ccc2c1</smiles><smiles>NS(=O)(=O)c1ccc2c(c1)C(=O)C1C=CC=CC1C2=O</smiles><smiles>COc1cccc(S(N)(=O)=O)c1C(=O)c1cccc(S(=O)(=O)O[Na])c1C</smiles><smiles>O=S(=O)([O-])c1cc(S(=O)(=O)O[Na])c2ccc3c(O)cc(S(=O)(=O)O[Na])c4ccc1c2c34</smiles>

Dye-5<smiles>O=S(=O)(O)c1cc(S(=O)(=O)O)c2ccc3c(S(=O)(=O)O[Na])cc(S(=O)(=O)O[Na])c4ccc1c2c43</smiles><smiles>Nc1ncnc2c1ncn2CCOC[R6]([O-])([O-])[O-]</smiles>

Adefovir sodium salt<smiles>Cc1nnc(SCC2=C(C(=O)O[N+](=O)[O-])N3C(=O)C(NC(=O)Cn4cnnn4)[C@H]3SC2)s1</smiles>

Cefazolin sodium salt

Dye-6<smiles>NC(=O)Cc1ccccc1Nc1c(Cl)cccc1Cl</smiles>

Diclofenac sodium<smiles>NC(=O)CCN(CCC(N)=O)CCN(CCC(N)=O)CCC(N)=O</smiles>

$X \sim$ PAMAM-2<smiles>NC(=O)CCC(NC(=O)C(CCC(N)=O)NC(=O)C(N)Cc1c[nH]c2ccccc12)C(N)=O</smiles>

Peptide-1 4 $(n=3,5,7,9)$

\author{
sDNA-1: $(\mathbf{A})_{5}$ DNA-1: $(\mathbf{T})_{5^{\bullet}}(\mathbf{A})_{5}$ \\ sDNA-2: (A) ${ }_{10}$ DNA-2: $(\mathbf{T})_{10} \cdot(\mathbf{A})_{10}$ \\ sDNA-3: $(\mathrm{T})_{5}$ \\ sDNA-4: $(\mathbf{T})_{10}$
}

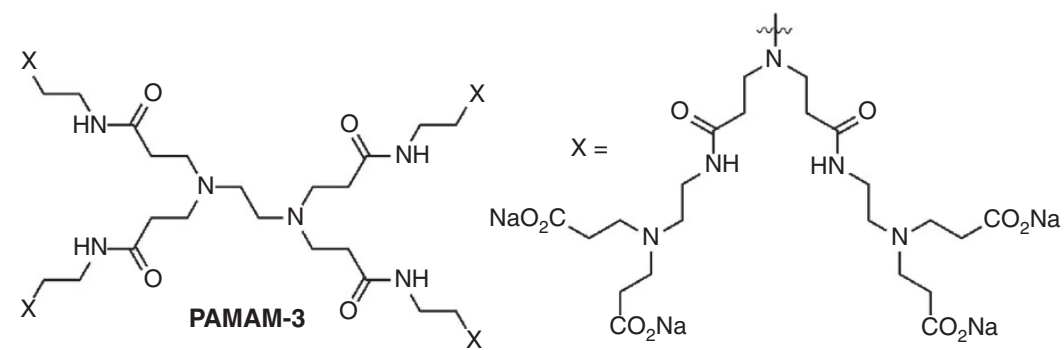

Figure 5 | Guest molecules. Structures of guests Dye-1 6, Drug-1 3, Peptide-1 4, sDNA-1 4, DNA-1 2 and dendrimers PAMAM-1 3.

complexes (Supplementary Figs 27-29). For comparison, all the experiments were carried out for the four mixtures by keeping the 2:1 molar ratio of the PP unit $(0.02 \mathrm{mM})$ and $\mathrm{CB}[8](0.01 \mathrm{mM})$.

It can be seen that all the 20 organic anions quenched the fluorescence of 1 much more efficiently than that of 2, 3 or 4 (Fig. 6a,b). For the 3D SOF solution of Com-Tetra, all the guests, with the exception of Dye-1 and PAMAM-1, could reach quenching saturation-a steady state when no more fluorescence change was observed upon addition of more guests (Fig. 6b-f). However, similar quenching saturation could not be realized by any of the guests tested for Com-M, Com-D and Com-Tri. Although quenching efficiency increased progressively from Com-M to Com-D to Com-Tri, which suggested multivalent interaction between the anionic guests and the cationic PP units of Com-D and Com-Tri, the much higher quenching efficiency for Com-Tetra relative to Com-Tri clearly suggests that ComTetra had an even stronger affinity towards guests, which may be attributed to the formation of the $3 \mathrm{D}$ framework that remarkably increased the apparent concentration of the PP unit in its interior and thus the overall electrostatic interaction. In the absence of $\mathrm{CB}[8]$, the same guest quenched the fluorescence of the PP unit of tetratopic $\mathbf{1}$ and tritopic $\mathbf{4}$ to a comparable extent, which further supported that it was the porous framework in Com-Tetra that caused the remarkable increase of the quenching efficiency. DLS experiments showed that after adding the guests, the $D_{\mathrm{H}}$ of ComTetra remained similar, which supported the high stability of the framework (Supplementary Fig. 25). It is noteworthy that all the quenching processes were quick and reached equilibrium within $1 \mathrm{~min}$, which was needed for preparing the mixture solution and recording the spectrum, implying that even large nano-sized guests, such as DNA-2 and PAMAM-3, could get into the interior of the $3 \mathrm{D}$ framework very quickly.

To collect more evidence for the inclusion of the guests in the interior of the porous framework in solution, we further performed DOSY experiments for Dye-1, Drug-2 and PAMAM-3. Their diffusion coefficient $(D)$ was determined to be $5.0 \times 10^{-10}, 3.9 \times 10^{-10}$ and $3.2 \times 10^{-10} \mathrm{~m}^{2} \mathrm{~s}^{-1}$ (Supplementary Figs 15-17), respectively. The values were all significantly larger than that $\left(4.8 \times 10^{-11} \mathrm{~m}^{2} \mathrm{~s}^{-1}\right)$ of ComTetra. When the guests were added to the aqueous solution of Com-Tetra, the DOSY experiments showed that the signals of all the three components gave rise to a comparable $D$ value (Supplementary Figs 18-20), which was actually identical to that of Com-Tetra. This result clearly indicated that the guest molecules were included into the interior of the 3D SOF and the framework of the SOF was still maintained after inclusion.

The above fluorescent and DOSY experiments also suggested that the new periodic framework was homogeneous. DOSY experiments gave rise to the identical result for the three samples after standing for 1 week, and centrifugation (8,000 r.p.m. for $1 \mathrm{~h}$ ) for COM-Tetra and its mixture solution with Dye-1, Drug-2 and PAMAM-1 did not lead to any observable precipitate. These observations further supported the homogeneous nature of the periodic framework.

The microcrystals of Com-Tetra, once formed, became insoluble in water even at the boiling temperature. At temperatures above $120^{\circ} \mathrm{C}$, the microcrystals slowly dissolved in water in a sealed pressure bottle. As expected, after evaporation of the solvent, microcrystals could be formed again after standing for days, which clearly reflected the reversible feature of the 
a

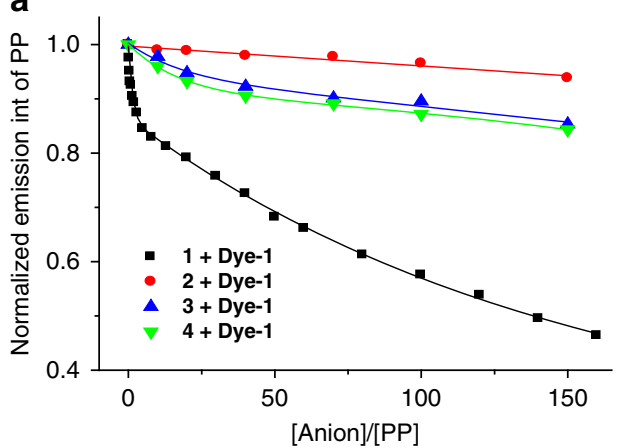

C
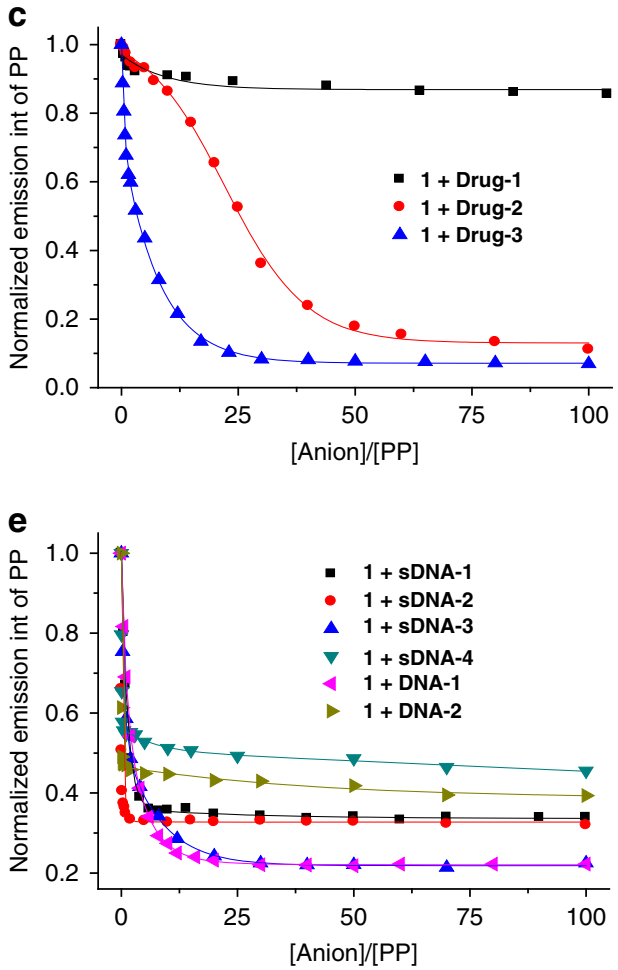

b

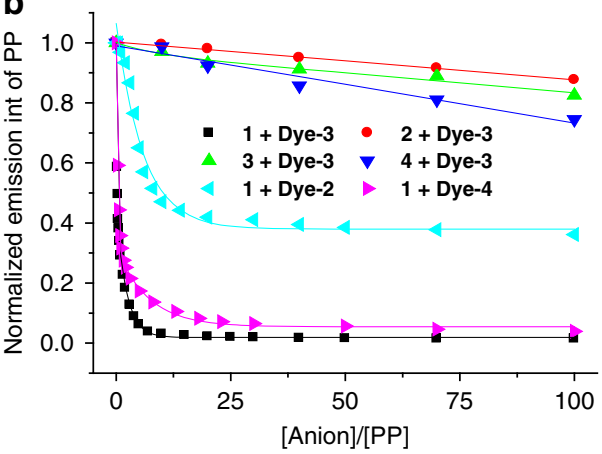

d

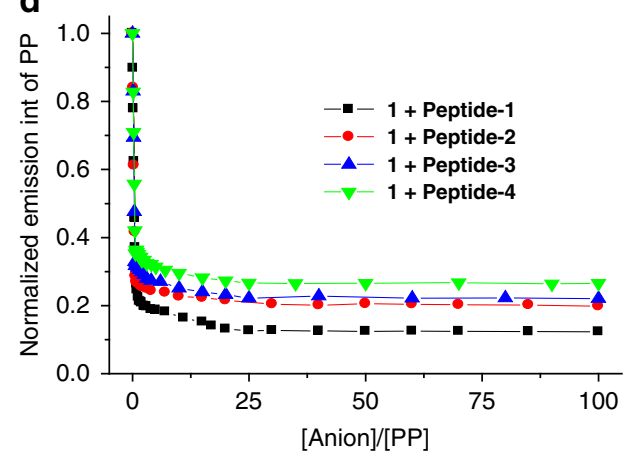

f

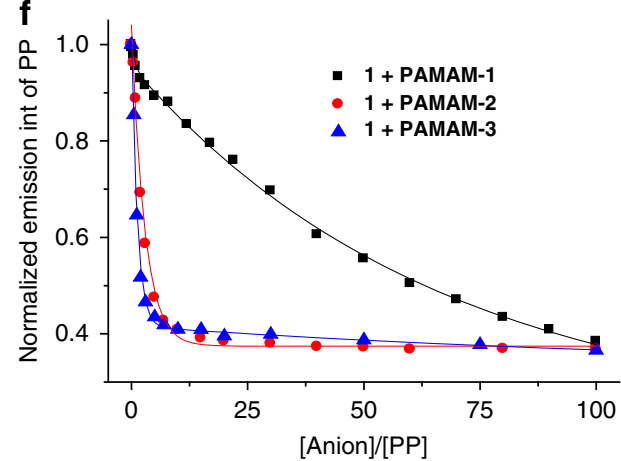

Figure 6 | Solution-phase fluorescence quenching experiments. Normalized fluorescence quenching of the PP unit $(0.02 \mathrm{mM})$ of 1-4 at $450 \mathrm{~nm}$ in water containing CB[8] (0.01 mM). (a) 1-4 by Dye-1. (b) 1-4 by Dye-2 4. (c) 1 by Drug-1 3. (d) 1 by Peptide-1 4. (e) 1 by sDNA-1 4 and DNA-1,2. (f) 1 by PAMAM-1 3. [anion] represents the total concentration of the anionic unit of the guests.

self-assembling process. The high stability of the microcrystals in water at room temperature made it possible to quantitatively evaluate their capacity of extracting conjugated anionic guests from their aqueous solutions using ultraviolet-visible (vis) spectroscopy. Similar to the solution behaviour, Com-Tetra functioned like an 'ion sponge' that displayed differential binding affinity towards a wide variety of organic anions. In a typical experiment, microcrystals $(1.0 \mathrm{mg}, 0.24 \mu \mathrm{mol})$ were immersed in an aqueous solution $(1.0 \mathrm{ml})$ of a guest compound whose anion concentration was made equal to the concentration of the PP unit of $\mathbf{1}$ in the microcrystals. The quantity of the guest in solution was measured using ultraviolet-vis spectroscopy by monitoring its characteristic absorption over a period of about $60 \mathrm{~h}$, from which the amount of the guest extracted by the 3D SOF was calculated. The results are provided in Fig. 7. It can be found that the extraction reached equilibrium for all the guests within $60 \mathrm{~h}$ except DNA-2, extraction for which was much slower. We tentatively attribute this exception to the large size of DNA, which has a diameter of about $2.0 \mathrm{~nm}$ and cannot easily pass the more rigid aperture of the SOF microcrystal ${ }^{48}$. This result also implied that in solution the homogeneous self-assembled SOF were elastic, and could be expanded to allow for quick inclusion of DNA-2, as evidenced by fast fluorescence quenching, and evaporation of the solvent might lead to its shrinking in the solid state. Remarkably, the absorption percentage of eight guests exceeded $75 \%$, and for trianion Dye-5 and tetraanion Dye-6, the adsorption was nearly quantitative $(>99 \%)$. These values may be lower limits because some of the SOF complex may have remained in solution, which should also absorb a little guest that could be detected. The X-ray diffraction profile of the microcrystals that quantitatively absorbed Dye-5 displayed a diffraction pattern similar to that of dye-free microcrystals (Supplementary Fig. 26), indicating that the periodic structure was maintained after guest absorption. This result is also consistent with the above solution-phase DLS experiments (Supplementary Fig. 25), supporting the high stability of the supramolecular framework in the microcrystals.

Release studies. The release properties of the drug-loaded microcrystals were further evaluated by exposing the isolated 
a

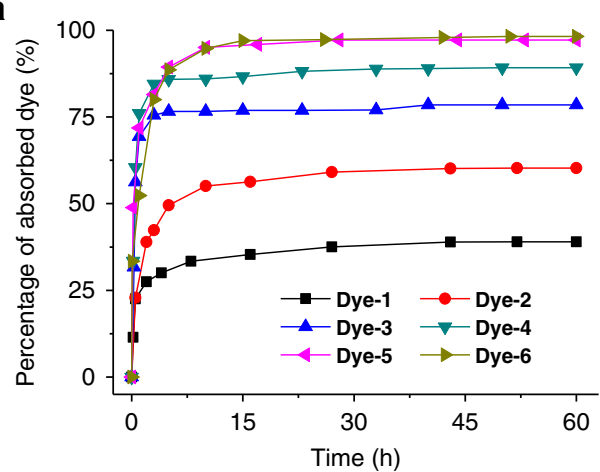

C

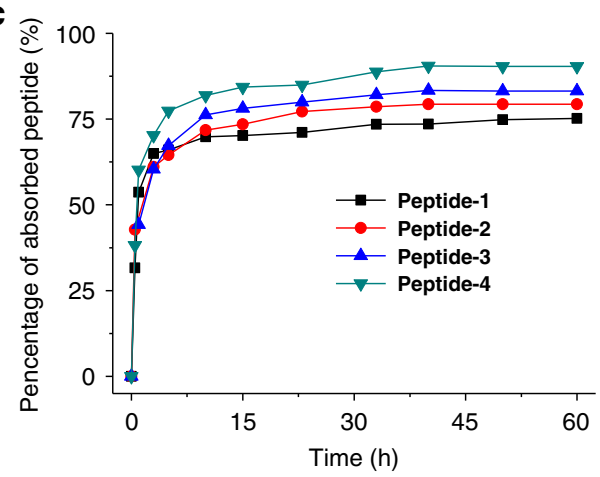

b
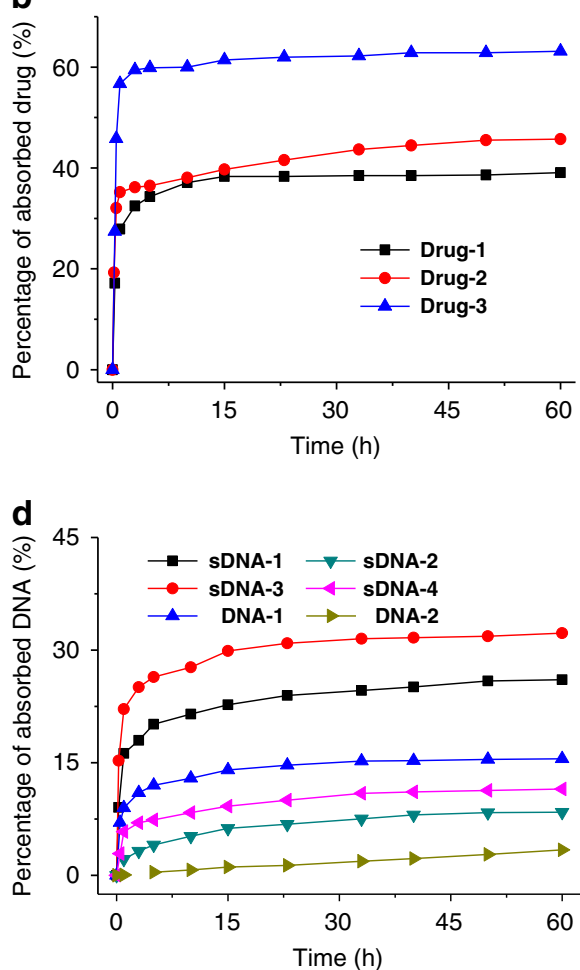

f

e
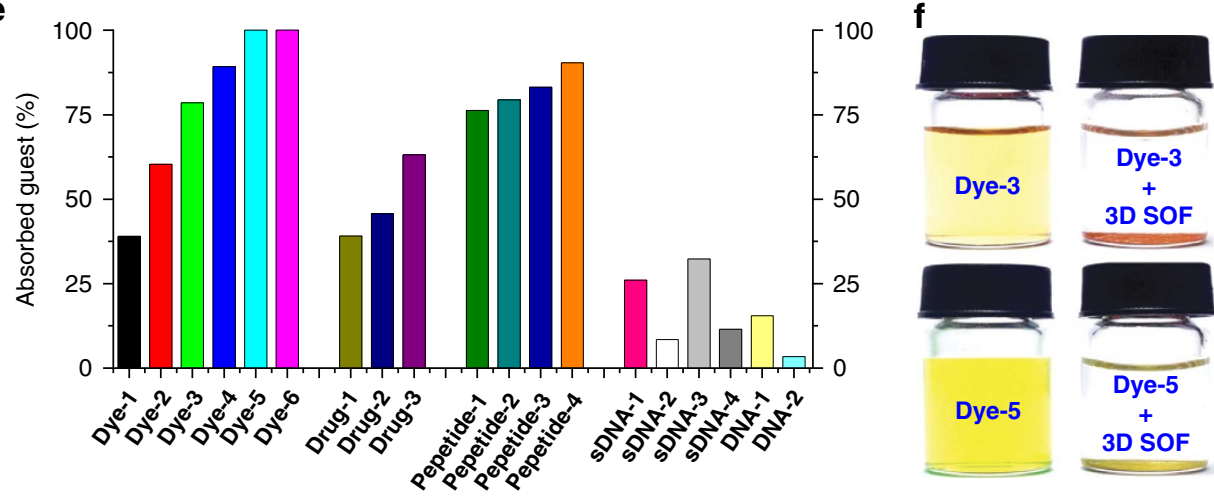

Figure 7 | Absorption studies. Percentage of guests absorbed from water by microcrystals $(1.0 \mathrm{mg})$ against time and sample pictures.

(a) Dye-1 6, (b) Drug-1 3, (c) Peptide-1 4, (d) sDNA-1 4 and DNA-1,2. (e) Percentage of guests absorbed by microcrystals after $60 \mathrm{~h}$ when the absorption reached equilibrium, except DNA-2. The initial anion concentration of all the guests was equal to [PP] of $\mathbf{1}$ of the microcrystals. The percentage was obtained from ultraviolet-vis absorption experiments. (f) The solution of Dye-3 and Dye-5 in water (left) and the identical solution after $60 \mathrm{~h}$ in the presence of microcrystals $(1.0 \mathrm{mg})$ (right).

microcrystals with pre-adsorbed Drugs $1 \sim 3$ in acidic media. For the first series of experiments, the microcrystals were immerged in $1 \mathrm{ml}$ of water at $37^{\circ} \mathrm{C}$ and then 1.0 equiv of hydrochloric acid relative to the molar amount of the $\mathrm{Na}^{+}$ion of the included guests was added. The $\mathrm{pH}$ was about $6.5-6.8$. The release profiles were determined by following the solution absorption of the drugs at different times (Fig. 8a). It can be seen that, when the release proceeded with the samples being static, after $60 \mathrm{~h}$, the drug release contents were 15, 8 and 94\% for Drug-1, Drug-2 and Drug-3, respectively. When the release occurred on a shaking orbital shaker, the release contents of Drug-1 and Drug-2 could be increased to 73 and $61 \%$, respectively. The acid-responsive drug release was reproduced in a slightly different aqueous media when the solution $\mathrm{pH}$ was kept at 4.5 using a $\mathrm{CH}_{3} \mathrm{CO}_{2} \mathrm{H} /$ $\mathrm{CH}_{3} \mathrm{CO}_{2} \mathrm{Na}$ buffer (Fig. 8b) ${ }^{49}$. When the samples were kept static, the release content for Drug-3 was $99 \%$ after $60 \mathrm{~h}$. When the release was conducted on a shaking orbital shaker, the release contents of Drug-1 and Drug-2 were increased from 21 and 13\% to 85 and $72 \%$, respectively.

Cytotoxicity test. Human cancer (HeLa) cells were used as the model to evaluate the in vitro cytotoxicity of Com-Tetra and the drug-contained Com-Tetra samples using the Cell Counting Kit-8 (CCK-8) assay. The results are provided in Fig. 9. It can be seen that the viability of the HeLa cells maintained at $91.8-96.6 \%$, $87.1-95.1 \%$ or $75.9-86.4 \%$ after incubating for $24 \mathrm{~h}$ with the samples at 50,100 and $200 \mu \mathrm{g} \mathrm{ml}^{-1}$, respectively. These preliminary results show that the cytotoxicity of the new 3D SOF is low ${ }^{50}$.

Gas adsorption. Nitrogen and carbon dioxide gas absorption capabilities of the microcrystals were also evaluated at -196 and $0{ }^{\circ} \mathrm{C}$, respectively, after the microcrystals were activated under 
a

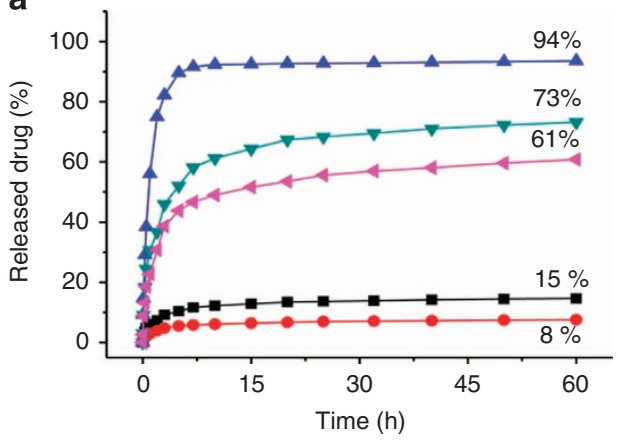

b

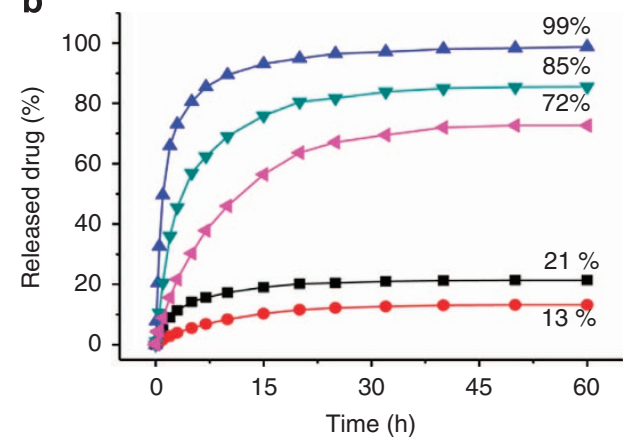

Figure 8 | Release of microcrystal (1 mg)-adsorbed drugs at $37^{\circ} \mathbf{C}$ against time. (a) $\ln 1.0 \mathrm{ml}$ of water containing 1.0 equiv of hydrochloric acid relative to the molar amount of the $\mathrm{Na}^{+}$ion of the attracted guests. (b) In $1.0 \mathrm{ml}$ of $\mathrm{CH}_{3} \mathrm{CO}_{2} \mathrm{H} / \mathrm{CH}_{3} \mathrm{CO}_{2} \mathrm{Na}(\mathrm{pH}=4.5)$ buffer. The experiments were conducted with the samples being in the static state (blue triangles: Drug-3, black squares: Drug-1 and red circles: Drug-2) or on a shaking orbital shaker (green triangles: Drug-1 and purple triangles: Drug-2).

a

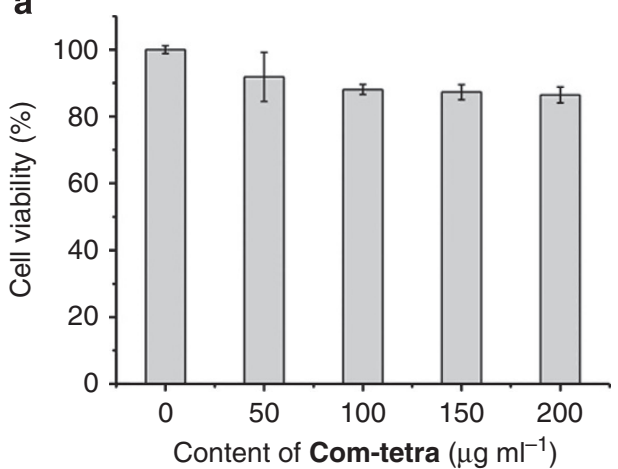

C

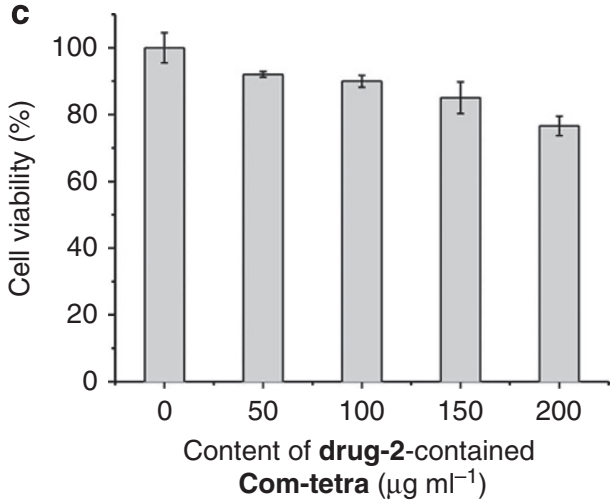

b

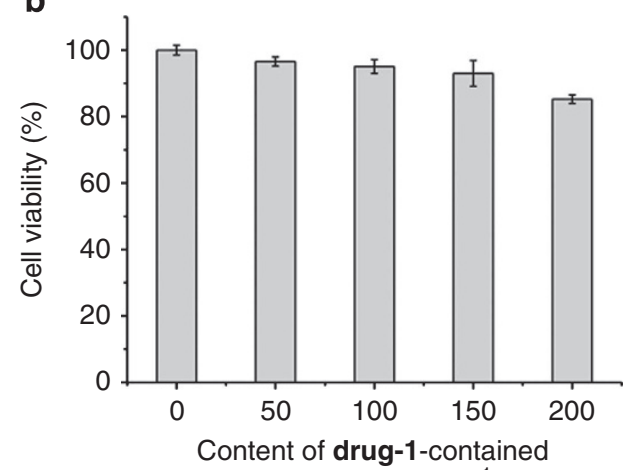

Com-tetra $\left(\mu \mathrm{g} \mathrm{ml}^{-1}\right)$

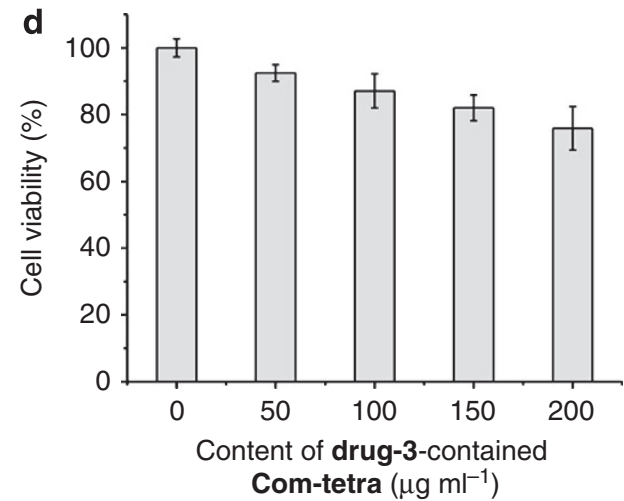

Figure 9 | Cytotoxicity of Com-Tetra. Cell viability values (\%) estimated by CCK-8 proliferation tests versus incubation concentrations microcrystals of (a) Com-Tetra. (b) Drug-1-contained Com-Tetra. (c) Drug-2-contained Com-Tetra. (d) Drug-3-contained Com-Tetra. HeLa cells ( $\sim 2 \times 10^{4}$ per well) were incubated with $50-200 \mu \mathrm{g} \mathrm{ml}^{-1}$ samples at $37^{\circ} \mathrm{C}$ for $24 \mathrm{~h}$. Error bars represent the s.d. of uncertainty for each point.

vacuum at $180^{\circ} \mathrm{C}$ for $10 \mathrm{~h}$ (Supplementary Figs 41 and 42 ). The nitrogen gas absorption amount was $5.4 \mathrm{~cm}^{3}(\mathrm{STP}) \mathrm{g}^{-1}$ at $P / P_{0}=1.0$, and the Brunauer-Emmett-Teller (BET) surface area of the microcrystals was $10.3 \mathrm{~m}^{2} \mathrm{~g}^{-1}$. The carbon dioxide gas absorption amount was $0.28 \mathrm{mmol} \mathrm{g}^{-1}$ at $800 \mathrm{~mm} \mathrm{Hg}$. The microcrystals after the activation still maintained the structural ordering because their X-ray diffraction profile was nearly the same as that of the sample before activation. These preliminary results show that the new supramolecular microcrystals are not good porous materials for gas absorption.

\section{Discussion}

We have successfully constructed the first periodic 3D SOF in solution using a robust self-assembling strategy in water. By virtue of the rigidity of the tetrahedral building block and the high stability of hydrophobically driven encapsulation that holds the building blocks together, the resulting periodic framework possesses high porosity that allows for inclusion of a variety of organic and biologically active guests into its interior. The solution-phase 3D framework represents a new type of ordered supramolecular polymer that resembles crystalline metal-organic frameworks and covalent organic frameworks in periodicity and porosity, but differs greatly by much enhanced reversibility and solution processability. It also provides new opportunities for the design of novel soft porous architectures. For example, stable ordered $3 \mathrm{D}$ polymers might be constructed after covalently locking the framework. Importantly, such a 3D framework can maintain the periodicity and porosity in the solid state. The 
resulting microcrystals are able to extract various guests from their solutions-in some cases even reaching a chargestoichiometric equilibrium-and release the included guests in a controllable manner. Such guest inclusion and release properties at the heterogeneous solid-liquid mixed phases also make the 3D SOF solid a great candidate for material applications such as membranes, sensors and controlled delivery.

\section{Methods}

Materials and measurements. All reagents were obtained from commercial suppliers and used without further purification unless otherwise noted. All reactions were carried out under a dry nitrogen atmosphere. All solvents were dried before use following standard procedures. Column chromatography was performed on silica gel (200-300 mesh), and thin-layer chromatography was performed on precoated silica gel plates $(0.4-0.5 \mathrm{~mm}$ thick $) .{ }^{1} \mathrm{H}$ and ${ }^{13} \mathrm{C}$ NMR spectra were recorded with a $400-\mathrm{MHz}$ spectrometer in the indicated solvents at $25^{\circ} \mathrm{C}$ (Supplementary Figs 30-37). Variable-temperature ${ }^{1} \mathrm{H}$ NMR spectra were recorded with a $500-\mathrm{MHz}$ spectrometer in the indicated solvents. ${ }^{1} \mathrm{H}$ NMR DOSY experiments were carried out with a 400 NMR spectrometer. Chemical shifts were referenced to the residual solvent peaks. Mass spectra (electrospray ionization) were obtained on Shimadzu LCMS-2010EV, IonSpec 4.7 Tesla FTMS and microTOF II spectrometers. DLS experiments were performed on a Malvern Zetasizer Nano ZS90 light-scattering Instrument. Powder X-ray diffraction measurements were carried out on a Bruker D8 Advance diffractometer at $40 \mathrm{kV}$ and $40 \mathrm{~mA}$ with $\mathrm{Cu} \mathrm{K} \alpha$ radiation $(\lambda=1.5406 \AA)$. Scanning electron micrographs and elemental distribution of the samples were obtained on a JSM-6330F Field Emission Scanning Electron Microscope combined with energy dispersive X-ray analysis. Transmission electron micrographs were recorded on a 2100F JEOL FETEM microscope at $120 \mathrm{kv}$ aligned for low dose $\left(10 \mathrm{e} \AA^{-2} \mathrm{~s}^{-1}\right)$ diffractive imaging. The synthesis and characterization, and spectroscopic measurements, including DLS, fluorescence, ultraviolet-vis absorption, thermogravimetric analysis, gas adsorption experiments and cytotoxicity experiments are summarized in the Supplementary Methods.

\section{Solution-phase synchrotron X-ray diffraction data collection. The X-ray} diffraction data were obtained at beamline BL14B1 of the Shanghai Synchrotron Radiation Facility at a wavelength of $1.2398 \AA$. BL14B1 is a beamline based on a bending magnet and a Si (111) double crystal monochromator was employed to monochromatize the beam. The size of the focus spot is about $0.5 \mathrm{~mm}$ and the end station is equipped with a Huber 5021 diffractometer. NaI scintillation detector was used for data collection.

Solid-phase synchrotron X-ray-scattering data collection. Synchrotron radiation SAXS experiments were performed on the BL16B beamline of Shanghai Synchrotron Radiation Facility, using a fixed wavelength of $0.124 \mathrm{~nm}$, a sample-todetector distance of $2.01 \mathrm{~m}$ and an exposure time of 2,000 s. The $2 \mathrm{D}$ scattering pattern was collected on a charge-coupled device camera, and the curve intensities versus $q$ were obtained by integrating the data from the pattern.

Solution-phase synchrotron SAXS data collection. The SAXS data were collected at the SIBYLS Beamline 12.3.1 of the Advanced Light Source (Lawrence Berkeley National Laboratory). The Com-Tetra $([\mathrm{PP}]=8 \mathrm{mM})$ complex in water were exposed for 0.5 and 1 , and $6 \mathrm{~s}$, followed by a 1 -s exposure to check for radiation damage, using a MARCCD X-ray detector system located $1.6 \mathrm{~m}$ from the sample chamber to collect data in the $q$-spacing $0.01-0.32 \AA^{-1}$, where $q=4 \pi \sin \theta$ / $\lambda(2 \theta$ is the scattering angle and $\lambda$ is the wavelength $(1.03 \AA)$ ). Filtrates resulting from the sample concentration process were exposed for equivalent times and the intensities were subtracted from the corresponding sample exposures. Data from the low- and high-resolution ranges of the respective short and long exposures were scaled and merged to obtain the final data sets shown in Fig. 3a.

\section{References}

1. Lehn, J.-M. Supramolecular chemistry-scope and perspectives: molecules, supermolecules, and molecular devices. Angew. Chem. Int. Ed. 27, 89-112 (1988).

2. Whitesides, G., Mathias, J. P. \& Seto, C. T. Molecular self-assembly and nanochemistry: a chemical strategy for the synthesis of nanostructures. Science 254, 1312-1319 (1991).

3. Desiraju, G. R. Crystal engineering: from molecule to crystal. J. Am. Chem. Soc. 135, 9952-9967 (2013).

4. Lehn, J.-M. Supramolecular polymer chemistry-scope and perspectives. Polym. Int. 51, 825-839 (2002).

5. De Greef, T. F. A. et al. Supramolecular polymerization. Chem. Rev. 109, 5687-5754 (2009).

6. Desiraju, G. R. Crystal engineering: a holistic view. Angew. Chem. Int. Ed. 46, 8342-8356 (2007).
7. Yang, W. et al. Exceptional thermal stability in a supramolecular organic framework: porosity and gas storage. J. Am. Chem. Soc. 132, 14457-14469 (2010).

8. Kitagawa, S., Kitaura, R. \& Noro, S.-i. Functional porous coordination polymers. Angew. Chem. Int. Ed. 43, 2334-2375 (2004).

9. Sarkar, M. \& Biradha, K. Crystal engineering of metal-organic frameworks containing amide functionalities: studies on network recognition, transformations, and exchange dynamics of guests and anions. Cryst. Growth Des. 7, 1318-1331 (2007).

10. Park, T., Zimmerman, S. C. \& Nakashima, S. A highly stable quadruply hydrogen-bonded heterocomplex useful for supramolecular polymer blends. J. Am. Chem. Soc. 127, 6520-6521 (2005).

11. de Greef, T. F. A. \& Meijer, E. W. Supramolecular polymers. Nature 453, 171-173 (2008).

12. Cordier, P., Tournilhac, F., Soulié-Ziakovic, C. \& Leibler, L. Self-healing and thermoreversible rubber from supramolecular assembly. Nature 451, 977-980 (2008).

13. Harada, A., Kobayashi, R., Takashima, Y., Hashidzume, A. \& Yamaguchi, H. Macroscopic self-assembly through molecular recognition. Nat. Chem. 3, 34-37 (2011).

14. Aida, T., Meijer, E. W. \& Stupp, S. I. Functional supramolecular polymers. Science 335, 813-817 (2012).

15. Bruns, C. J. \& Stoddart, J. F. Supramolecular polymers molecular machines muscle up. Nat. Nanotech. 8, 9-10 (2013).

16. Appel, E. A., del Barrio, J., Loh, X. J. \& Scherman, O. A. Supramolecular polymeric hydrogels. Chem. Soc. Rev. 41, 6195-6214 (2012).

17. Liu, Y., Wang, Z. \& Zhang, X. Characterization of supramolecular polymers. Chem. Soc. Rev. 41, 5922-5932 (2012).

18. Yan, X., Wang, F., Zheng, B. \& Huang, F. Stimuli-responsive supramolecular polymeric materials. Chem. Soc. Rev. 41, 6042-6065 (2012).

19. Castellano, R. K., Clark, R., Craig, S. L., Nuckolls, C. \& Rebek, Jr J. Emergent mechanical properties of self-assembled polymeric capsules. Proc. Natl Acad. Sci. USA 97, 12418-12421 (2000)

20. Singh, A. et al. Branched DNA that forms a solid at $95^{\circ} \mathrm{C}$. Angew. Chem. Int Ed. 50, 3227-3231 (2011).

21. Zhou, C. et al. A three-dimensional cross-linking supramolecular polymer stabilized by the cooperative dimerization of the viologen radical cation. Polym. Chem. 5, 341-345 (2014).

22. Liu, Y. et al. Porphyrin-containing hyperbranched supramolecular polymers: enhancing ${ }^{1} \mathrm{O}_{2}$-generation efficiency by supramolecular polymerization. Polym. Chem. 6, 53-56 (2014).

23. Zhang, K.-D. et al. Toward a single-layer two-dimensional honeycomb supramolecular organic framework in water. J. Am. Chem. Soc. 135, 17913-17918 (2013).

24. Yaghi, O. M. et al. Reticular synthesis and the design of new materials. Nature 423, 705-714 (2003).

25. Horike, S., Shimomura, S. \& Kitagawa, S. Soft porous crystals. Nat. Chem. 1, 695-704 (2009).

26. Cote, A. P. et al. Porous, crystalline, covalent organic frameworks. Science 310, 1166-1170 (2005).

27. Beaudoin, D., Maris, T. \& Wuest, J. D. Constructing monocrystalline covalent organic networks by polymerization. Nat. Chem. 5, 830-834 (2013).

28. Furukawa, H., Cordova, K. E., O’Keeffe, M. \& Yaghi, O. M. The chemistry and applications of metal-organic frameworks. Science 341, 974 (2013).

29. Ding, S.-Y. \& Wang, W. Covalent organic frameworks (COFs). From design to applications. Chem. Soc. Rev. 42, 548-568 (2013).

30. Ma, S. \& Zhou, H.-C. Gas storage in porous metal-organic frameworks for clean energy applications. Chem. Commun. 46, 44-53 (2010).

31. D’Alessandro, D. M., Smit, B. \& Long, J. R. Carbon dioxide capture: prospects for new materials. Angew. Chem. Int. Ed. 49, 6058-6082 (2010).

32. Keskin, S., van Heest, T. M. \& Sholl, D. S. Can metal-organic framework materials play a useful role in large-scale carbon dioxide separations? ChemSusChem 3, 879-891 (2010).

33. Li, J.-R., Sculley, J. \& Zhou, H.-C. Metal-organic frameworks for separations. Chem. Rev. 112, 869-932 (2012).

34. Kreno, L. E. et al. Metal-organic framework materials as chemical sensors. Chem. Rev. 112, 1105-1125 (2012).

35. Chen, B., Xiang, S. \& Qian, G. Metal-organic frameworks with functional pores for recognition of small molecules. Acc. Chem. Res. 43, 1115-1124 (2012).

36. Horcajada, P. et al. Metal-organic frameworks in biomedicine. Chem. Rev. 112, 1232-1268 (2012).

37. Rocca, J. D., Liu, D. \& Lin, W. Nanoscale metal-organic frameworks for biomedical limaging and drug delivery. Acc. Chem. Res. 44, 957-968 (2011).

38. McKinlay, A. C. et al. BioMOFs: Metal-organic frameworks for biological and medical applications. Angew. Chem. Int. Ed. 49, 6260-6266 (2010).

39. Yoon, M., Srirambalaji, R. \& Kim, K. Homochiral metal-organic frameworks for asymmetric heterogeneous catalysis. Chem. Rev. 112, 1196-1231 (2012). 
40. Liu, Y., Xuan, W. \& Cui, Y. Engineering homochiral metal-organic frameworks for heterogeneous asymmetric catalysis and enantioselective separation. Adv. Mater. 22, 4112-4135 (2010).

41. Corma, A., Garcia, H. \& Llabrés i Xamena, F. X. Engineering metal organic frameworks for heterogeneous catalysis. Chem. Rev. 110, 4606-4655 (2010).

42. Ko, Y. H., Kim, E., Hwang, I. \& Kim, K. Supramolecular assemblies built with host-stabilized charge-transfer interactions. Chem. Commun. 13, 1305-1315 (2007).

43. Zhang, Y. et al. Encapsulation enhanced dimerization of a series of 4-aryl-Nmethylpyridinium derivatives in water: new building blocks for self-assembly in aqueous media. Chem. Asian J. 9, 1530-1534 (2014).

44. Liu, S. et al. The cucurbit[n]uril family: prime components for self-sorting systems. J. Am. Chem. Soc. 127, 15959-15967 (2005).

45. Cohen, Y., Avram, L. \& Frish, L. Diffusion NMR spectroscopy in supramolecular and combinatorial chemistry: an old parameter-new insights. Angew. Chem. Int. Ed. 44, 520-554 (2005).

46. Accelrys Materials Studio Release Notes, Release 5.0 (Accelrys Software Inc.: San Diego, 2008).

47. Zhang, Z.-J., Zhang, Y.-M. \& Liu, Y. Controlled molecular self-assembly behaviors between cucurbituril and bispyridinium derivatives. J. Org. Chem. 76, 4682-4685 (2011).

48. Mecozzi, S. \& Rebek, Jr J. The 55\% solution: a formula for molecular recognition in the liquid state. Chem. Eur. J. 4, 1016-1022 (1998).

49. Chou, L. Y. T., Ming, K. \& Chan, W. C. W. Strategies for the intracellular delivery of nanoparticles. Chem. Soc. Rev. 40, 233-245 (2011).

50. Foucault-Colleta, A. et al. Lanthanide near infrared imaging in living cells with $\mathrm{Yb}^{3+}$ nano metal organic frameworks. Proc. Natl Acad. Sci. USA 110, 17199-17204 (2013).

\section{Acknowledgements}

We acknowledge the Ministry of Science and Technology (2013CB834501), the Ministry of Education (IRT1117, Doctor Fellowship Grant), and the National Natural Science Foundation $(91227108,21228203$ and J1103304) of China and the Science and
Technology Commission of Shanghai Municipality (13NM1400200) for financial support, and Shanghai Synchrotron Radiation Facility for providing BL14B1 beamline for collecting the solution-phase synchrotron X-ray diffraction data. Y.L. thanks the support from the Molecular Foundry, Lawrence Berkeley National Laboratory, supported by the Office of Science, Office of Basic Energy Sciences, Scientific User Facilities Division, of the US Department of Energy under Contract No. DE-AC02-05CH11231.

\section{Author contributions}

Z.-T.L., D.-W.Z. and Y.L. conceived and designed the research, analysed the data and composed the manuscript. J.T. carried out most of the experiments, analysed the data and composed the manuscript. T.-Y.Z., S.-C.Z., S.A., M.V.A. and S.-H.X. carried out part of the experiments. H.W. and X.Z. analysed the data. All authors discussed and commented on the manuscript.

\section{Additional information}

Supplementary Information accompanies this paper at http://www.nature.com/ naturecommunications

Competing financial interests: The authors declare no competing financial interests

Reprints and permission information is available online at http://npg.nature.com/ reprintsandpermissions/

How to cite this article: Tian, J. et al. Three-dimensional periodic supramolecular organic framework ion sponge in water and microcrystals. Nat. Commun. 5:5574 doi: $10.1038 /$ ncomms6574 (2014)

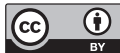

This work is licensed under a Creative Commons Attribution 4.0 International License. The images or other third party material in this article are included in the article's Creative Commons license, unless indicated otherwise in the credit line; if the material is not included under the Creative Commons license, users will need to obtain permission from the license holder to reproduce the material. To view a copy of this license, visit http://creativecommons.org/licenses/by/4.0/ 